\title{
APRENDIZAGEM COLABORATIVA COMO ESTRATÉGIA DE METODOLOGIA ATIVA NA EDUCAÇÃO ONLINE
}

\author{
RIO DE JANEIRO/RJ FEVEREIRO/2018
}

\author{
Marta Teixeira do Amaral Amaral Montes - UNESA - marta.amaralmontes@gmail.com \\ Renato Cardoso de Oliveira - UNESA - recocardoso@hotmail.com \\ Karoline Costa Cassiano - UNESA - cassianokaroline@gmail.com \\ Jadir Magno dos Montes - UNESA - jadirmag@gmail.com
}

Tipo: Investigação Científica (IC)

Natureza: Relatório Final de Pesquisa

Categoria: Conteúdos e Habilidades

Setor Educacional: EDUCAÇÃO SUPERIOR

\begin{abstract}
RESUMO
Este artigo tem a finalidade de descrever alguns resultados de uma pesquisa qualitativa realizada em uma universidade no Rio de Janeiro que teve como objetivo analisar a funcionalidade pedagógica do fórum de discussão nos cursos a distância em Letras/Inglês e quais estratégias metodológicas são utilizadas pelos professores no ensino online. O referencial teórico está fundamentado nos seguintes autores: Stahl e Dillenbourg, Edwards, Pallof e Pratt, Behrens, Lévy e Vigotski. A coleta de dados foi realizada mediante o grupo focal com seis professores da EaD. Foram selecionadas, a priori, algumas categorias de análise para compor o estudo e utilizado o método de análise de conteúdo. Utilizou-se a técnica da análise temática para interpretar os dados coletados. Os resultados apontaram que embora os professores reconheçam que a EaD é uma modalidade que demanda postura docente diferenciada e instituiu novas relações com o conhecimento, ainda não conseguiram distanciar-se completamente do exercício da pedagogia da transmissão e transpor a lógica da linearidade. A adaptação do ambiente presencial para o cenário virtual ainda é um aspecto forte na modalidade online. Os entrevistados percebem que a interatividade é um fator primordial para que o conhecimento seja construído no ambiente virtual mas ficou evidente que os processos colaborativos precisam ainda ser desenvolvidos pelos professores nos fóruns de discussão sob a perspectiva do modelo todos-todos. Os dados coletados com professores serviram de base para a análise sobre a colaboração e do modelo comunicacional no fórum de discussão, visando analisar as categorias da colaboração e da construção do conhecimento coletivo a partir da interação no ambiente online do fórum.
\end{abstract}

Palavras-chave: Aprendizagem colaborativa. Metodologias Ativas. Docência Online. Interatividade. Educação a Distância.

\section{AGRADECIMENTOS}

AO GRUPO DE PESQUISA ÉTICA E EDUCAÇÃO ONLINE DO PIBIC/UNESA E AO PROGRAMA PESQUISA E PRODUTIVA UNESA 2017. 


\section{I - INTRODUÇÃO}

Este artigo tem o objetivo de descrever alguns resultados de uma pesquisa qualitativa que teve como objetivo identificar a funcionalidade pedagógica do fórum de discussão e as estratégias metodológicas utilizadas pelos professores no ensino a distância na modalidade online. O problema de pesquisa versou sobre o seguinte questionamento: a aprendizagem colaborativa, apoiada pela teoria sociointeracionista e pelos recursos da aprendizagem apoiada por computador, pode contribuir para aprimorar os processos comunicacionais no fórum de discussão e na prática docente online?

$\mathrm{Na}$ tentativa de entendermos a importância da colaboração na educação online e sua continuidade, utilizaremos neste trabalho as definições de aprendizagem colaborativa dos seguintes autores: Gerry Stahl (1996), Pierre Dillenbourg (1999), Palloff e Pratt (2012) e Marilda Behrens (2002). No entanto, poderemos fazer menção a outros pesquisadores que também tratam do tema.

Stahl (1996) define que a aprendizagem colaborativa apoiada por computador (CSCL) é uma área das ciências da aprendizagem que estuda como as pessoas aprendem em grupo e mediadas pelos computadores. Afirma que é um processo mediante o qual indivíduos negociam e compartilham entendimentos relevantes à resolução do problema posto por alguém (STAHL; KOSCHMANN; SUTHERS; 2006). Dillenbourg (1999) aborda a questão ressaltando a importância da diferenciação entre cooperação e colaboração, ou seja, aprendizagem cooperativa e aprendizagem colaborativa. Para esse autor, na cooperação os alunos dividem a proposta solicitada em vários fragmentos, resolvem as subtarefas, individualmente e, posteriormente, juntam os resultados parciais formando um único trabalho. Na abordagem cooperativa, a aprendizagem é realizada por indivíduos que colaboram com seus resultados individuais e apresentam a sua agregação como o produto final do grupo. Para Dillenbourg (1999), aprender em grupos cooperativos é visto como algo que se realiza individualmente e equivale às dinâmicas tradicionais do ensino, em que cada aluno realiza uma parte do trabalho e faz a junção dessas partes no momento da apresentação da atividade. Enquanto, na aprendizagem colaborativa há uma interação total e simultânea dos participantes para a resolução do problema.

Vigotski (1998) concebe uma abordagem desenvolvimentista do conhecimento tendo o meio sócio-histórico do aprendiz importância particular, porque contém as ferramentas técnicas e semióticas que serão utilizadas para o desenvolvimento do psiquismo e da formação do pensamento desse estudante (LEGENDRE, 2010). 
O conceito de aprendizagem colaborativa, embora pareça recente, já foi defendido por muitos estudiosos ou educadores, ainda que com outros nomes. Definida como "uma situação em que duas ou mais pessoas aprendem ou tentam aprender algo em conjunto" (DILLENBOURG, 1999, p. 05), podemos vincular esta definição aos pressupostos de várias pedagogias, ao longo da história da Educação. Dewey (1959), na teoria escolanovista, entende que o indivíduo é um "ser vivo de funções ativas e especiais que se desenvolvem pela redireção e combinação em que entram quando se põem em contato ativo com o seu ambiente" (DEWEY, 1959, p. 77). A aprendizagem colaborativa poderia, então, buscar os pressupostos teóricos nas tendências pedagógicas dos movimentos da Escola Nova ou nas propostas pedagógicas de Dewey, bem como na abordagem teórica do sociointeracionismo de Vigotski (1998) ou no Paradigma da Complexidade que entende que a aprendizagem é um processo que acontece mediante a união entre a abordagem progressista, a visão holística e o ensino com pesquisa (BEHRENS, 1999, p. 89) e que esses componentes conjunturais promovem $\mathrm{o}$ uso de metodologias de ensino mais coesas às exigências contemporâneas.

Stahl (1996) define a aprendizagem colaborativa com suporte computacional como uma área das ciências da aprendizagem que estuda como as pessoas aprendem em grupo e mediadas por computador. Ainda afirma que é um processo através do qual, indivíduos negociam e compartilham entendimentos relevantes à resolução do problema posto. Dillenbourg (1999) aborda a questão, ressaltando a importância da diferenciação entre cooperação e colaboração, ou seja, aprendizagem cooperativa e aprendizagem colaborativa. Para esse autor, na cooperação, os alunos dividem a proposta solicitada em vários fragmentos, resolvem as subtarefas, individualmente, de forma assíncrona e, posteriormente, juntam os resultados parciais, formando um único trabalho. Nessa abordagem, a aprendizagem é realizada por indivíduos que colaboram com seus resultados individuais e apresentam a sua agregação como o produto final do grupo. Aprender em grupos cooperativos é visto como algo que se realiza individualmente e equivalente às metodologias tradicionais de ensino. Em contrapartida, o processo colaborativo (DILLENBOURG, 1999) pressupõe a realização conjunta do trabalho. A colaboração é uma "atividade coordenada resultado de uma tentativa contínua de construir e manter um entendimento compartilhado sobre um problema" (STAHL; KOSCHMANN; SUTHERS; 2006, p. 8).

Embora utilizem formas diferentes para conceituar a aprendizagem colaborativa, fica evidente que os autores concordam que é um processo de interação contínua e de construção conjunta e mútua entre os membros de um determinado grupo com o objetivo de buscar conhecimentos e competências. Processos colaborativos são 
indispensáveis em diversas esferas sociais, exigindo do sujeito social competências para transitar entre elas. A realidade social apresenta múltiplas provocações tanto ao indivíduo como à Educação, assim como enormes desafios para o futuro, mas, sobretudo, a educação é "condição necessária e indispensável à humanidade na construção de novos ideais, da liberdade e da construção social" (DELORS, 2010, p.19). A educação superior e suas demandas não se excluem do cenário colocado acima. Tampouco a educação online.

\section{II - Procedimentos metodológicos}

Como instrumento de coleta de dados foi utilizada a técnica do grupo focal. Foram convidados dez professores, no entanto, apenas 6 compareceram. A atividade foi realizada com esse grupo de professores que ministram disciplinas no curso de graduação a distância de uma universidade particular no estado do Rio de Janeiro. Os objetivos da pesquisa eram: (1) investigar a avaliação desses docentes acerca da funcionalidade pedagógica do fórum de discussão para a construção de aprendizado colaborativo; (2) averiguar a importância dada pelos professores aos processos de colaboração e se estes se constituíam para eles uma estratégia didática na construção do conhecimento acadêmico. A pesquisadora atuou como facilitadora e ficou responsável pelo encaminhamento das perguntas, mediação dos comentários e condução da discussão do grupo. Uma câmera de vídeo ficou afixada em um ponto da sala e a atividade teve duração de $01 \mathrm{~h} 15 \mathrm{~min}$ sendo inteiramente gravada por meio audiovisual, transcrita na íntegra e autorizada pelos participantes. A discussão no grupo focal iniciou-se com temas de caráter geral para facilitar a abordagem e a participação imediata dos integrantes. Inicialmente fizemos a seguinte pergunta: Questão A (de caráter geral) - Como você percebe a educação no Brasil e a educação online. Em seguida, foram propostas questões mais específicas e de caráter analítico no que tange à docência online: o que é ser professor online? Como são realizadas as mediações de conteúdo? Ações para superação das dificuldades?

As informações coletadas constituíram o corpus do estudo e os dados originários da atividade do grupo focal foram interpretados utilizando-se a "análise de conteúdo" (BARDIN, 2002) e finalmente, a última fase do tratamento foi a inferência, ou seja, a interpretação dos dados recolhidos. Esse procedimento permite que o conteúdo pesquisado se constitua "em dados quantitativos e/ou análises reflexivas em observações individuais e gerais das entrevistas" (BARDIN, 2002; p. 78).

III - Interpretação dos resultados da pesquisa 
A categoria inicial refere-se à "mediação e a coordenação das atividades realizadas no fórum de discussão". Neste item, as respostas dos professores divergiram no que tange ao modelo pedagógico e de educação. Indicaram dois polos opostos. De um lado, as respostas de alguns professores expuseram, de maneira clara, a prática da pedagogia da transmissão e da transposição do ambiente presencial para o cenário virtual, conforme afirma o entrevistado C: "(...) na mediação a gente tira as dúvidas do aluno, busca auxiliar o aluno para que ele vá para o caminho correto que é apreender" (ENTREVISTADO C). Essa declaração expõe o comportamento passivo e receptivo do docente, à medida que ele acredita que mediação é somente atender a uma solicitação de esclarecimento de dúvidas. Por isso seu comportamento é o de esperar por um pedido do aluno. Caso não haja dúvida, não há interação.

A mediação pedagógica busca abrir caminhos e novas relações com o educando, a aprendizagem, os conteúdos, as áreas do conhecimento, os contextos e, especialmente com os outros sujeitos envolvidos no processo (PEREZ; CASTILLO, 1999). Tem como características o diálogo permanente, as trocas de experiências, os debates a partir das dúvidas levantadas, as problematizações, a orientação sobre conteúdo e dificuldades técnicas que o aluno tenha e, sobretudo, o intercâmbio entre aprendizagem e sociedade (MORAN; MASETTO; BEHRENS, 2012).

O professor desnuda-se da roupagem histórica da transmissão de informações para vestir-se de orientador do aluno, consultor de trabalho, com o objetivo de dinamizar a aprendizagem do grupo. Essa perspectiva vê a educação como um meio propício à ação do sujeito-educando em um ambiente problematizador, complexo e interrelacional.

De outro lado, ainda nesta categoria, outro professor manifesta que mediar 0 conhecimento no fórum de discussão "é tecer uma série de novas tarefas, tanto para o aluno quanto para o professor" (ENTREVISTADO B). Na fala de outro professor percebemos ora nuances tradicionais ora progressistas, como se ainda não tivesse entendido bem o processo de ensinar e aprender na modalidade online:

\footnotetext{
...em prática continuamos desenvolvendo o processo tradicional de comunicar conhecimento (faz gesto de doar com as mãos), porém, o ensino online exige de certa maneira que esse trabalho de coordenação do conhecimento seja cada vez mais distribuído entre alunos e professores (ENTREVISTADO A).
}

Este fragmento aponta para a discussão do processo ensino e aprendizagem e assinala os conceitos de ensinar e de aprender. Enquanto o primeiro (ensinar) está diretamente ligado ao professor que, mediante suas ações, facilita a construção dos conhecimentos pelos alunos, o segundo está associado com o aluno, sujeito do processo de aprendizagem que deve buscar e adquirir conhecimento, ressignificar os conteúdos, 
produzir reflexões, pesquisar, dialogar, "debater, desenvolver competências pessoais e profissionais, atitudes éticas, políticas, integrar conceitos..." (MORAN; MASETTO; BEHRENS, 2012, p. 139).

Como visto no primeiro depoimento, parece-nos que aquele professor ainda é cativo da antiga prática docente que valoriza o conteúdo e o ensinamento como fatores basilares no processo educativo. Privilegiando a técnica da transmissão para transferência de informações. As atividades do fórum, sob está ótica, passam a ser apenas obrigação da disciplina, réplicas dos exercícios feitos na sala de aula presencial sem qualquer interferência no desenvolvimento integral do aluno: "espírito e corpo, inteligência, sensibilidade, sentido estético, responsabilidade pessoal, espiritualidade" (DELORS, 2010, p. 99). Tampouco, ajuda o aluno na elaboração de pensamentos autônomos ou na formulação de seus próprios juízos de valor ou tomada de decisão em sua vida social (DELORS, 2010).

Não obstante, as falas de outros docentes conotaram a possibilidade de um trabalho pedagógico diferenciado na modalidade online porque este exige uma mudança no processo de aprendizagem, bem como um comportamento mais ativo tanto para professor quanto para aluno. O segundo precisa ser colocado como protagonista do processo de aprendizagem na perspectiva da colaboração.A mediação tecnológica na educação impõe desafios à prática docente atual, como exposto no depoimento anterior. O trabalho do professor precisa revestir-se de uma ação pedagógica que conduza à produção do conhecimento e à construção de um sujeito reflexivo e inovador independente do espaço geográfico, da idade ou da origem desse indivíduo. O vínculo que une o grupo é a interação, a colaboração e a vontade de estar no AVA. Um aspecto marcante, nessa categoria, é a identificação de a maioria dos professores entrevistados ainda compreenderem a mediação como um processo unilateral e individual: “(...) na aula online isso não se dá, a interação é individual" (ENTREVISTADO F).

Os depoimentos mostram uma discrepância entre o que se propõe para processos de mediação utilizando as tecnologias digitais e as falas dos professores na categoria mediação. Enquanto defendemos que não se pode educar para a vida sem uma educação colaborativa e participativa (PEREZ e CASTILLO, 1999), compreendemos nas falas dos professores, na sua maioria, que a educação a distância (EaD) tem sido feita de maneira unilateral, solitária e dentro da perspectiva da transmissão, abrindo espaço para mais um modelo comunicacional: o de um-um. Talvez, esteja aí uma das dificuldades de mantermos os alunos no ambiente virtual de aprendizagem, porque eles vivenciam espaços digitais onde todos se comunicam com todos, como por exemplo: o Facebook ou os grupos de Whatsapp. 
As novas tecnologias interativas romperam com o paradigma tradicional moderno, com a linearidade da transmissão das informações e com modelo comunicacional unidirecional. Entretanto, percebemos que muito ainda temos que aprender no tocante à $\mathrm{EaD}$, pois a prática docente nesta modalidade ainda está pautada na fragmentação clássica da emissão/professor X recepção/alunos (SILVA, 2002).

\section{CONSIDERAÇÕES FINAIS}

A pesquisa evidencia que a interação é uma estratégia metodológica relevante na ação pedagógica no fórum de discussão. É, portanto o ponto alto da ação didática. $O$ fórum constitui-se em elemento fundamental para o desenvolvimento da educação online, pois ele configura o espaço da discussão, da construção e da desconstrução de ideias, valores e conceitos. As metodologias e estratégias da docência online devem objetivar a construção do trabalho colaborativo mediado pela ação participativa de professor e alunos em um processo contínuo de aprendizagem.

O fórum de discussão não poderá empregar somente a linguagem escrita em detrimento de outras linguagens e recursos hipermidiáticos. Isso restringe o uso da interface, subutiliza o AVA como meio colaborativo e, sobretudo, dificulta o desenvolvimento de metodologias que envolvam atividades criativas, interdisciplinares e colaborativas. Por isso, a necessidade da associação das diferentes mídias e ferramentas colaborativas (muitas fora do AVA) às exigências internas de cada disciplina da graduação.

Destacamos como contribuições eficientes para a educação online, a aprendizagem colaborativa e a metodologia de projetos como exemplo de metodologias ativas na aprendizagem. Ambas se constituem em subsídios basais para ações pedagógicas desafiadoras coerentes com as exigências do mundo contemporâneo, pois as necessidades hodiernas determinam a formação de pessoas e profissionais que acompanhem a evolução do conhecimento e assumam o trabalho de forma consciente, crítica e participativa, manifestando características apropriadas à participação social, ao compromisso político e à cidadania.

As evidências da pesquisa apontam que se torna necessária uma mudança atitudinal no que tange ao cenário educativo online. Professores e alunos precisam deixar seus postos de emissor e receptor de mensagens educativas, respectivamente. $O$ comportamento dos sujeitos deve ser o da colaboração e não simplesmente o da cooperação que são representados por trabalhos realizados separadamente e depois agrupados para apresentação - no processo dialógico do aprendizado. 
Há a exigência de que os planejamentos pedagógicos para a docência online se preocupem também com os aspectos atitudinais do aluno, à medida que ele é um ser que pensa, sente, dúvida, levanta hipóteses e elabora a vida no contexto da realidade complexa, dinâmica e indeterminada. Ser aluno, na era das redes sociais, é conceber e entender o mundo através da interação representada na evolução frenética das TIC e na expansão da realidade no ciberespaço. Por isso a prática pedagógica contemporânea deve romper com os limites redutores e lineares da educação tradicional e conectar-se a uma ação didática complexa e interativa, objetivando alargar o desenvolvimento intelectual e acadêmico dos aprendizes, bem como, propiciar que as discussões nos fóruns consistam em proveitosos momentos na vida acadêmica do aluno e contribuam para o amadurecimento afetivo e intelectual do grupo numa perspectiva dialógica e de construção de conhecimento significativo.

Entendemos que os processos comunicacionais no fórum podem ser aperfeiçoados com a mediação docente baseada na colaboração discente e que utilizem um modelo comunicacional aberto e ativo que conduza o estudante por um roteiro ativo diante da construção do conhecimento. Assinalamos a necessidade de que os planejamentos didáticos para o EaD se empenhem no desenvolvimento de competências discursivas, técnicas, cognitivas, comunicativas, interpessoais, dialógicas e profissionais. Isso porque o estudante é um ser social que pensa, sente, dúvida, levanta hipóteses, e elabora a vida no contexto da realidade complexa, dinâmica e indeterminada. As metodologias didáticas utilizadas devem, então, eleger uma abordagem progressista para que se construa uma pedagogia que visualize o ambiente digital como meio para que a educação se processe mediante a atuação de seus protagonistas: alunos e professores (MONTES, 2016).

\section{REFERÊNCIAS}

ALCÂNTARA, P. R; LEITE, C.L.K; PASSOS, M.O de A; TORRES, P.L; A aprendizagem colaborativa na educação a distância on-line. PUC- Paraná, 2005. Disponível em http://www.abed.org.br/congresso2005/por/pdf/171tcc3.pdf. Acesso feito em 20 de abril de 2015.

BARDIN, L. Análise de conteúdo. São Paulo: 70, 2002.

BEHRENS, M. A. Projetos de aprendizagem colaborativa num paradigma emergente. In MORAN, J. M; MASETTO, M. T; BEHRENS, M. A. Novas Tecnologias e mediação pedagógica. 19. ed. São Paulo: Papirus, 2012. 
DELORS, J. (Org.) Educação: um tesouro a descobrir: relatório para a Unesco da Comissão Internacional sobre Educação para o século XXI. 4.ed. Trad.: Guilherme João de Freitas Teixeira. Brasília: UNESCO, 2010.

DEWEY, J. Democracia e educação. Tradução: Godofredo Rangel e Anísio Teixeira. 3.ed. São Paulo: Nacional. $1959 . \quad$ Disponível http:/www.bvanisioteixeira.ufba.br/artigos/congresso2.html. Acesso feito em 02 de fevereiro de 2016.

Dillenbourg, P. Introduction: What Do You Mean By Collaborative Learning?. In Pierre Dillenbourg (Ed.), Collaborative Learning: Cognitive and Computational Approaches. Amsterdam: Pergamon, 1999. Disponível em http://tecfa.unige.ch/tecfa/publicat/dilpapers-2/Dil.7.1.14.pdf . Acesso feito em 15 de maio de 2015.

MONTES, M. T. do A. Aprendizagem Colaborativa e Docência Online: Curitiba: Appris, 2016.

MORAN, J. M. Pedagogia integradora do presencial-virtual. 2002. Disponível em http://www.abed.org.br/congresso2002/trabalhos/texto50.htm. Acesso feito em 26 de maio de 2016.

PALLOF, R. M.; PRATT, K. O aluno virtual: um guia para trabalhar com estudantes on-line Porto Alegre: Artmed, 2002.

PEREZ. F. G e CASTILLO, D. P. La mediación pedagógica. Buenos Aires: Ciccus, 1999.

STAHL, G., KOSSCHMANN, T., \& SUTHERS, D. Computer-supported collaborative learning: An historical perspective. In R. K. Sawyerge. Handbook of the learning sciences. Cambridge, UK, 2006, p.p 409 -426

VIGOTSKI, L. A formação social da mente. São Paulo: Martins Fontes, 1998. 